\title{
INDUCED TACHYCARDIA: ITS EFFECT UPON THE CORONARY HEMODYNAMICS, MYOCARDIAL METABOLISM AND CARDIAC EFFICIENCY OF THE INTACT DOG ${ }^{1,2}$
}

\author{
By GEORGE M. MAXWELL, CESAR A. CASTILlO, DOUGLAS H. WHiTE, JR., \\ CHARLES W. CRUMPTON, AND GEORGE G. ROWE 3
}

\author{
(From the Cardiovascular Research Laboratory and the Departments of Pediatrics and Medicine, \\ University of Wisconsin, Madison, Wis.)
}

(Submitted for publication January 13, 1958; accepted June 26, 1958)

The relationship of the heart rate to the coronary blood flow had been studied for many years. Thus, in 1926 Anrep and Segall (1) felt that coronary flow was independent of heart rate unless anoxia or excess of carbon dioxide supervened. Katz, Jochim and Bohning in 1938 (2), using an isolated heart preparation, declared that "changes in heart rate produced no change in the coronary inflow and sinus outflow or in the sinus outflow/ coronary inflow ratio."

Gregg (3) in 1950 stated that the evidence was conflicting and that no definite statement could be made concerning the effect of rate upon the coronary blood flow. In particular, he himself noted no change when the heart was electrically driven. Wégria, Wang and Glaviano (4) in 1955 stimulated the left atrial appendage and recorded an increase in the coronary blood flow, together with a fall in the systemic arterial blood pressure and cardiac output. In 1956 Laurent, Bolene-Williams, Williams and Katz (5) showed a direct relationship between heart rate and coronary flow, as did Duff, Berglund and Borst (6); a reduction in left coronary flow with slowing of the heart was observed by Starzl, Gaertner and Baker (7).

All of the studies quoted were carried out in isolated heart preparations, heart-lung preparations, or "open-chest" animals. Clearly no ideal circumstance can be encompassed, but it was felt

1 This study was supported in part by grants from the National Heart Institute, National Institutes of Health, Public Health Service; Wisconsin Heart Association; and the Research Committee of the Graduate School, University of Wisconsin, from funds supplied by the Wisconsin Alumni Research Foundation.

2 Presented at the National Meeting, American Federation for Clinical Research, Atlantic City, N. J., May, 1957.

${ }^{3}$ John and Mary R. Markle Foundation Scholar. that a study could be designed utilizing an intact animal, anesthetized but breathing room air, in order further to test the inter-relationship of heart rate, coronary blood flow and cardiac efficiency.

\section{METHOD}

Nine healthy mongrel dogs, unselected by age or sex, were studied. Their weights varied from 15 to $25 \mathrm{Kg}$. Morphine sulfate was injected intramuscularly in a dose of $3 \mathrm{mg}$. per $\mathrm{Kg}$.; one hour later pentobarbital (12 mg. per $\mathrm{Kg}$.) was given intravenously.

By way of the superficial neck veins, cardiac catheters were placed under fluoroscopic guidance in the pulmonary artery, coronary sinus and right atrium. A Cournand needle was placed percutaneously in the femoral artery. The airway was maintained by a cuffed endotracheal tube; apart from the periods of coronary flow study, the animal breathed room air. Each catheter and the arterial needle were connected to a manifold system of stopcocks by short plastic tubes. The volume of these latter was adjusted so that simultaneous samples were obtained from the coronary sinus, femoral artery and pulmonary artery.

Cardiac output was determined by the Fick principle; the expired air was collected for five minutes in a Tissot spirometer connected to the endotracheal tube by a system of one-way flutter valves. The blood samples from the femoral and pulmonary arteries were drawn at the midpoint of the air collection. Femoral and pulmonary arterial pressures were recorded at the beginning and end of the cardiac output. The cardiac rate was determined by standard limb-lead electrocardiograms; respirations were monitored by a pneumograph connected to a straingage manometer and recorded on a Sanborn polyviso. Expired air samples were analyzed for oxygen and carbon dioxide in the Scholander apparatus (8). Duplicate checks to within 0.02 per cent were required. Blood oxygen and carbon dioxide contents were measured in duplicate by the method of Van Slyke and Neill (9). The results were required to check within 0.2 volume per cent. Pressures were measured by Statham straingage manometers and graphically recorded on a Sanborn polyviso. Mean pressures were obtained by electronic integration. Resistances were calculated from the 
TABLE I

Metabolic changes consequent to induced tachycardia

\begin{tabular}{|c|c|c|c|}
\hline & Control* & Tachycardia* & "p" valuet \\
\hline 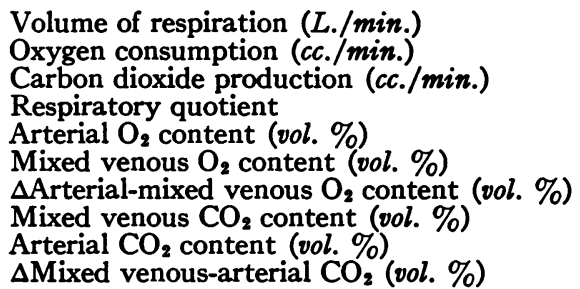 & $\begin{array}{r}2.9 \pm 0.1 \\
104 \pm 18 \\
78 \pm 17 \\
0.76 \pm 0.07 \\
17.1 \pm 2.4 \\
12.9 \pm 2.5 \\
4.3 \pm 0.8 \\
48.5 \pm 6.8 \\
45.4 \pm 7.3 \\
3.0 \pm 0.8\end{array}$ & $\begin{array}{r}3.3 \pm 1.2 \\
116 \pm 27 \\
98 \pm 26 \\
0.77 \pm 0.05 \\
16.9 \pm 2.6 \\
12.2 \pm 2.7 \\
4.7 \pm 0.6 \\
47.1 \pm 6.7 \\
44.0 \pm 7.0 \\
3.2 \pm 0.7\end{array}$ & $\begin{array}{l}>0.6 \\
<0.05 \\
>0.1 \\
>0.7 \\
>0.7 \\
>0.3 \\
>0.3 \\
>0.4 \\
>0.4 \\
>0.6\end{array}$ \\
\hline
\end{tabular}

* Mean and standard deviation.

$\dagger$ Tests significance of change.

Poiseuille equation, and works by the laws of dynamics. The formulae used are quoted by Wiggers (10).

Control cardiac output was measured one hour after the intravenous pentobarbital. A steady state was assessed by the presence of sinus arrhythmia, respiratory rate of 12 to 14 per minute, and a steady level of unconsciousness.

Immediately after the control cardiac output the control coronary flow was measured by the nitrous oxide method of Kety and Schmidt (11) as modified for the coronary circulation (12). In all determinations the form of the saturation curve satisfied the criteria of the authors cited. Pressures in the femoral and pulmonary arteries were measured at the mid- and endpoints of the flow. On completion of the control measurements, tachycardia was induced.

Induction of tachycardia: Method. A commercial stimulator ${ }^{4}$ was employed. A needle contact was placed subcutaneously over the dog's apex beat. The other terminal was attached to a piano wire stylet traversing the right atrial catheter; the stylet terminated in a metal contact at the tip of the catheter, ${ }^{5}$ which was maneuvered against the right atrial wall until stimulation of the latter

4 Morris clinical pacemaker, Levinthal Electronic Products, Redwood City, Calif.

5 This device was designed by Dr. C. A. Castillo. produced a consistent tachycardia. Stimulation was continued for an average of seven minutes before the cardiac output and coronary flow were re-estimated by the methods already described. The total period of tachycardia averaged 25 minutes. In five dogs tachycardia followed the control study; in four it preceded the control observations.

Left heart weight estimation. The animal was sacrificed at the end of the study and the heart excised. The great vessels and atria were trimmed to their origins, the coronary sinus was ligated, and the coronary arteries to the left heart isolated; into the latter was injected the dye T1824 (Evans' blue). This entered the distribution of the left coronary bed and diffused through the corresponding muscle (13). Using this as a guide, the stained area of the left ventricle and septum (usually about 50 per cent of the latter) was excised and weighed wet. This figure was thought to give a relatively accurate measure of the weight of heart muscle supplied by the left coronary circulation.

The efficiency of the heart (ratio of actual mechanical work of the left ventricle to the energy equivalent of the oxygen consumption of the left heart) was calculated by ordinary thermodynamics applying the formula quoted by Katz and Mendlowitz (14). The oxygen consumption of the arrested heart was excluded in these calculations.

TABLE II

Systemic and pulmonary hemodymamics consequent to induced tachycardia

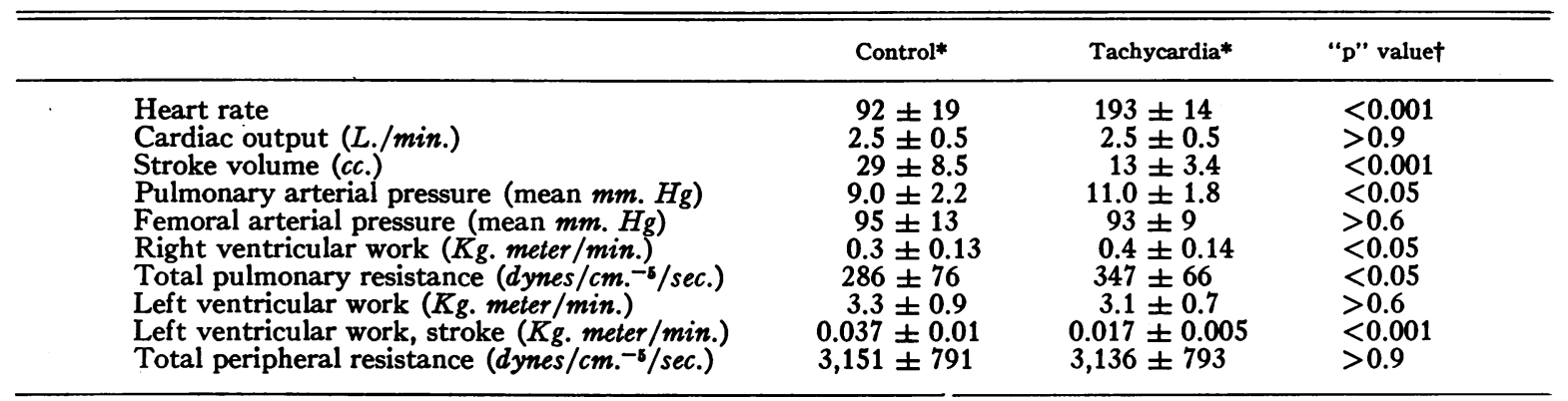

* Mean and standard deviation.

$\dagger$ Tests significance of change. 


\section{RESULTS}

In the tables the figures presented are means with standard deviations. A " $\mathrm{p}$ " value of 0.05 or less was considered significant. It is implicit that "statistically significant" change is not necessarily "physiologically significant."

Review of all of the factors reported in Table I (General Body Metabolism) shows that only the oxygen consumption rose significantly (104 to 116 cc. per minute); the induction of tachycardia does not apparently change the general metabolism of the animal except in this respect.

In Table II are seen the changes in the systemic and pulmonary hemodynamics due to the induction of tachycardia. The heart rate rises from an average of 92 to 193 beats per minute, and this is not associated with any change in cardiac output although the stroke volume decreases significantly.

The rise in pulmonary arterial pressure, though small, is significant; it is reflected in definite increases both in pulmonary arterial resistance and right ventricular work. The absence of any significant fall in femoral arterial pressure is reflected in the values for left ventricular work and peripheral resistance, neither of which showed any real change. The tachycardia was, however, associated with a definite fall in left ventricular stroke work.
It is seen, therefore, that the method of inducing tachycardia did not cause any very profound changes in the general metabolism or systemic hemodynamics.

The results concerning coronary hemodynamics, myocardial metabolism of oxygen and carbon dioxide, and cardiac efficiency are presented in Table III. In reviewing the coronary hemodynamics, it is seen that the coronary blood flow rose significantly and, conversely, the coronary vascular resistance fell. Coronary flow per beat was unchanged. The figures for the oxygen and carbon dioxide metabolism of the heart show that no significant difference in the oxygen or carbon dioxide contents of the coronary sinus blood was achieved. As their arterial counterparts did not change, the differences between the two did not vary either. The cardiac metabolic rates for oxygen and carbon dioxide rose with a high degree of significance, but the cardiac respiratory quotient was unaffected. The oxygen consumption of the weighed heart rose with a high degree of significance. In the face of the tachycardia, however, the cardiac oxygen consumption per beat was unchanged. The measures of efficiency (index of efficiency, coronary blood flow/left ventricular work ratio, or calculated "absolute" efficiency) each showed a significant decrement.

TABLE III

Coronary hemodynamics, myocardial metabolism of $\mathrm{O}_{2}$ and $\mathrm{CO}_{2}$, and cardiac efflciency consequent to induced tachycardia

\begin{tabular}{|c|c|c|c|}
\hline & Control* & Tachycardia* & "p" valuet \\
\hline $\begin{array}{l}\text { Coronary flow }(c c . / 100 \mathrm{Gm} . / \text { min.) } \\
\text { Coronary flow } / \text { beat }(c c .) \\
\text { Coronary vascular resistance (units) } \\
\left.\text { Coronary sinus } \mathrm{O}_{2} \text { content (vol. } \%\right) \\
\Delta \text { Arterial-coronary sinus } \mathrm{O}_{2}(\text { vol. } \%) \\
\left.\text { Coronary sinus } \mathrm{CO}_{2} \text { content (vol. } \%\right) \\
\Delta \text { Coronary sinus-arterial } \mathrm{CO}_{2}(\text { vol. } \%)\end{array}$ & $\begin{array}{r}81 \pm 14 \\
0.95 \pm 0.26 \\
1.2 \pm 0.24 \\
4.5 \pm 1.4 \\
12.3 \pm 2.7 \\
53.9 \pm 7.3 \\
9.5 \pm 2.6\end{array}$ & $\begin{array}{r}148 \pm 34 \\
0.84 \pm 0.28 \\
0.7 \pm 0.2 \\
4.2 \pm 1.3 \\
13.2 \pm 2.9 \\
53.4 \pm 7.6 \\
9.8 \pm 2.4\end{array}$ & $\begin{array}{l}<0.001 \\
>0.1 \\
<0.01 \\
>0.3 \\
>0.1 \\
>0.6 \\
>0.5\end{array}$ \\
\hline $\begin{array}{l}\text { Cardiac metabolic rate-oxygen } \\
(\text { cc. } / 100 \mathrm{Gm} \text {. myocardium } / \text { min. })\end{array}$ & $9.4 \pm 2.6$ & $18.5 \pm 5.5$ & $<0.001$ \\
\hline $\begin{array}{l}\text { Cardiac metabolic rate-carbon dioxide } \\
\text { (cc./100 Gm. myocardium/min.) } \\
\text { Cardiac respiratory quotient }\end{array}$ & $\begin{array}{l}7.5 \pm 1.8 \\
0.76 \pm 0.08\end{array}$ & $\begin{aligned} 14.1 & \pm 3.7 \\
0.7 & \pm 0.05\end{aligned}$ & $\begin{array}{l}<0.001 \\
>0.4\end{array}$ \\
\hline $\begin{array}{l}\text { heart weight }(c c . / 100 \mathrm{Gm} \text {./min.) } \\
\text { Myocardial } \mathrm{O}_{2} \text { consumption/beat }(c c .) \\
\text { Index of efficiency ( } \mathrm{LV} \text { work } \div \mathrm{CMRO} \text { ) } \\
\text { Ratio, coronary blood flow /left ventricular work } \\
\text { Calculated efficiency ( } \% \text { by Joule's Law) }\end{array}$ & $\begin{array}{l}8.3 \pm 1.4 \\
0.09 \pm 0.037 \\
0.38 \pm 0.11 \\
25.3 \pm 6.7 \\
24.0 \pm 9.0\end{array}$ & $\begin{array}{l}17.3 \pm 7.4 \\
0.09 \pm 0.06 \\
0.19 \pm 0.06 \\
48.6 \pm 11.9 \\
12.0 \pm 5.0\end{array}$ & $\begin{array}{l}<0.001 \\
>0.8 \\
<0.001 \\
<0.001 \\
<0.001\end{array}$ \\
\hline \multicolumn{4}{|c|}{ Mean heart weight $($ left ventricle + free septal wall) $=90.0 \mathrm{Gm} . ;$ range, $69-127 \mathrm{Gm}$. } \\
\hline
\end{tabular}

* Mean and standard deviation.

$\dagger$ Tests significance of change. 
The hemoglobin and hematocrit values showed no significant change in the course of the study, nor did the figures for $\mathrm{pH}^{6}$ in the arterial or coronary sinus blood change significantly. In six dogs estimations of lactate, pyruvate and glucose levels in arterial and coronary sinus blood were made (15-17). Considerable scatter without significant change was found in these values.

\section{DISCUSSION}

The variability of results in previous studies concerning the relationship of coronary flow to the heart rate has been commented upon by Gregg (3). This is probably in part due to the "nonintact" preparations used. The present study was designed around an intact animal, attempting to simulate clinical supraventricular tachycardia in which an abnormal pacemaker suddenly becomes dominant. No effort was made to control such conditions as left ventricular work or cardiac output. This perhaps reflects the clinical tachycardias more accurately. In any event, this policy was justified insofar as no significant change accrued in these and associated factors. The increases in body oxygen consumption and carbon dioxide production correspond with similar changes in myocardial oxygen and carbon dioxide metabolism.

It will have been noted that "just significant" increases in pulmonary arterial préssure and right ventricular work are here recorded. There is no "a priori" reason to suppose that these changes should affect conclusions concerning the left-sided coronary flow. However, utilizing similarly prepared animals and methods, a balloon-tipped catheter was placed in one of the main branches of the pulmonary artery and inflated. Thus a doubling of right ventricular work was obtained,

6 Measured in a Cambridge $\mathrm{pH}$ meter. but no significant change in left coronary hemodynamics or myocardial metabolism was found (see results in Appendix). It was felt then that theses to be presented were not vitiated by the pulmonary changes mentioned.

In the acceleration study discussed here, the striking phenomenon is the correlation of the coronary flow with the heart rate. As the arterial/ coronary sinus oxygen differences did not vary greatly, the changes in the cardiac metabolic rates for oxygen and carbon dioxide were a function of the increased coronary flow, or primarily of the increase in heart rate.

The tachycardia, in paralleling the coronary flow, did not cause any real change in the myocardial oxygen consumption per beat although the effective stroke work fell significantly. Laurent and his colleagues (5) have shown no direct relationship between the stroke work and stroke oxygen consumption. Our study confirms this.

On all counts the cardiac efficiency fell, whether assessed by a calculated "index" value, left ventricular work/coronary flow relationship, or by direct calculation from heart weight. The importance of the heart rate in determining ultimate myocardial efficiency has been emphasized by Sarnoff and co-workers (18), employing a supported isolated heart preparation. Their concept of a tension-time index (aortic systolic mean pressure $X$ duration of systole) suggests that this figure has a direct relationship to the cardiac metabolic rate for oxygen and hence to flow and efficiency. It has been further suggested (19) that the product of rate and systolic pressure, or rate and diastolic pressure, bears a relationship to Sarnoff's tension-time index.

Due to the difficulty of measuring the duration of systole in the arterial tracing as obtained by a

TABLE IV

Products of rate and systemic pressures

\begin{tabular}{lccc}
\hline \hline & Control* & Tachycardia* & "p" valuet \\
\hline Rate $\times$ systolic pressure & $11,593 \pm 3,128$ & $21,564 \pm 3,565$ & $<0.01$ \\
Rate X diastolic pressure & $6,728 \pm 1,705$ & $13,546 \pm 2,178$ & $<0.05$ \\
Rate $\times$ mean pressure & $8,641 \pm 2,340$ & $17,299 \pm 2,330$ & $<0.05$ \\
Cardiac metabolic rate- $-\mathrm{O}_{2}$ & $9.4 \pm 2.6$ & $18.5 \pm 5.5$ & $<0.001$ \\
$(c c . / 100 \mathrm{Gm}$. myocardium/min.) & & & \\
\hline
\end{tabular}

* Mean and standard deviation.

+ Tests significance of change. 
Cournand needle, the tension-time index was not calculable in the present study. However, when systolic or diastolic systemic pressures measured here are multiplied by the heart rate (Table IV), there is a marked increase in these figures in the presence of an induced tachycardia. Since neither the systolic nor diastolic pressures changed greatly, these products are increased primarily because of the increase in heart rate. The figures quoted in Table IV relate directly to the increased coronary blood flow and cardiac metabolic rate for oxygen ( $r$ values equal 0.6 to 0.8 ).

It would seem, therefore, that within limits it is more efficient to deliver the same amount of cardiac work at a slow heart rate than a fast one.
In the latter circumstance, energy is inadequately converted to useful work and must appear in some other form, e.g., heat.

\section{SUMMARY AND CONCLUSIONS}

In the intact anesthetized dog it appears that the heart rate has a close relationship to coronary flow volume when the heart is electrically accelerated.

Induced tachycardia does not profoundly alter general hemodynamics but it greatly increases coronary blood flow, cardiac oxygen consumption and carbon dioxide production. In the circumstances described, a profound fall in heart efficiency is recorded.

\section{APPENDIX}

Effect of increase of right ventricular work upon the left-sided coronary bed (eight studies)

\begin{tabular}{|c|c|c|c|}
\hline & Control* & Experimental* & "p" valuet \\
\hline $\begin{array}{l}\text { Right ventricular work }(\mathrm{Kg} . / \mathrm{M} . / \mathrm{min} .) \\
\text { Cardiac output }(\mathrm{L} . / \mathrm{min} .) \\
\text { Coronary blood flow }(c c . / 100 \mathrm{Gm} . / \mathrm{min} .) \\
\text { Cardiac metabolic rate- } \mathrm{O}_{2}(c c . / 100 \mathrm{Gm} . / \mathrm{min} .) \\
\text { Cardiac metabolic rate-- } \mathrm{CO}_{2}(c c . / 100 \mathrm{Gm} . / \mathrm{min} .)\end{array}$ & $\begin{array}{r}0.3 \pm 0.02 \\
2.6 \pm 1.0 \\
82 \pm 30 \\
10.6 \pm 5.0 \\
8.4 \pm 5.4\end{array}$ & $\begin{aligned} 0.6 & \pm 0.2 \\
2.7 & \pm 1.2 \\
81 & \pm 33 \\
12.5 & \pm 5.0 \\
10.6 & \pm 6.1\end{aligned}$ & $\begin{array}{l}<0.01 \\
>0.2 \\
>0.5 \\
>0.2 \\
>0.1\end{array}$ \\
\hline
\end{tabular}

* Figures are mean and standard deviation.

$\dagger$ Tests significance of change.

\section{REFERENCES}

1. Anrep, G. V., and Segall, H. N. The regulation of the coronary circulation. Heart 1926, 13, 239.

2. Katz, L. N., Jochim, K., and Bohning, A. The effect of the extravascular support of the ventricles on the flow of the coronary vessels. Amer. J. Physiol. 1938, 122, 236.

3. Gregg, D. E. Coronary Circulation in Health and Disease. Philadelphia, Lea and Febiger, 1950, p. 131 .

4. Wégria, R., Wang, H. H., and Glaviano, V. V. The mechanism of cardiac failure in tachycardia (abstract). J. clin. Invest. 1955, 34, 970.

5. Laurent, D., Bolene-Williams, C., Williams, F. L., and Katz, L. N. The effects of heart rate on coronary flow and cardiac oxygen metabolism. Amer. J. Physiol. 1956, 185, 355.

6. Duff, F., Berglund, E., and Borst, H. The effect of heart rate on ventricular function and coronary circulation in dogs. Amer. J. Physiol. 1955, 183, 611.

7. Starzl, T. E., Gaertner, R. A., and Baker, R. R. Acute complete heart block in dogs. Circulation $1955,12,82$.

8. Scholander, P. F. Analyzer for accurate estimation of respiratory gases in one-half cubic centimeter samples. J. biol. Chem. 1947, 167, 235.
9. Van Slyke, D. D., and Neill, J. M. The determination of gases in blood and other solutions by vacuum extraction and manometric measurement. I. J. biol. Chem. 1924, 61, 523.

10. Wiggers, C. J. Physiology in Health and Disease, 5th ed. Philadelphia, Lea and Febiger, 1949, pp. 593 and 714.

11. Kety, S. S., and Schmidt, C. F. The nitrous oxide method for the quantitative determination of cerebral blood flow in man: Theory, procedure and normal values. J. clin. Invest. 1948, 27, 476.

12. Eckenhoff, J. E., Hafkenschiel, J. H., Harmel, M. H., Goodale, W. T., Lubin, M., Bing, R. J., and Kety, S. S. Measurement of coronary flow by the nitrous oxide method. Amer. J. Physiol. 1948, 152, 356.

13. Eckenhoff, J. E., Hafkenschiel, J. H., and Landmesser, C. M. The coronary circulation in the dog. Amer. J. Physiol. 1947, 148, 582.

14. Katz, L. N., and Mendlowitz, M. Heart failure analyzed in the isolated heart circuit. Amer. J. Physiol. 1938, 122, 262.

15. Barker, S. B., and Summerson, W. H. The colorimetric determination of lactic acid in biological material. J. biol. Chem. 1947, 138, 535. 
16. Friedemann, T. E., and Haugen, G. E. Pyruvic acid. II. The determination of keto acids in blood and urine. J. biol. Chem. 1943, 147, 415.

17. Folin, O., and Malmros, $H$. An improved form of Folin's micromethod for blood sugar determinations. J. biol. Chem. 1929, 83, 115.

18. Sarnoff, S. J., Braunwald, E., Welch, G. H., Jr., Case, R. B., Stainsby, W. N., and Macruz, R.
Hemodynamic determinants of oxygen consumption of the heart with special reference to the tension-time index. Amer. J. Physiol. 1958, 192, 148.

19. Maxwell, G. M., Castillo, C. A., White, D. H., Jr., and Crumpton, C. W. The effects of serotonin (5-hydroxytryptamine) upon systemic, pulmonary, and coronary hemodynamics and metabolism (abstract). J. Lab. clin. Med. 1957, 50, 930. 